\title{
Engaging torture survivors in the global fight against torture
}

\author{
Berta Soley ${ }^{1}$
}

In front of the current ongoing debate on the need to actively engaging torture survivors in the global fight against torture, IRCT held a webinar at the request of IRCT member centres. The webinar examined torture survivor engagement in the rehabilitation process of rebuilding lives, seeking justice and torture prevention.

Lived experience can be emancipating and also paralysing, but foremost, it is precious to combat what has been suffered in the first person (Henry, 2021). How to recognise that contribution and engage torture survivors in the global fight against torture? What role do survivors play in society? How to involve survivors in advocacy and policy-making processes? What are the existing power (in)balances at play? Who gets to decide whether a survivor should speak up or not? Acknowledging that it can prompt some organisational, therapeutic, and professional considerations, what are the limits? How do we ensure that the survivor's well-being is protected along the process? To what extend should survivors be engaged in our organisation's decision-making?
1) Knowledge Development Focal Point and Editor Associate, International Rehabilitation Council for Torture Victims, Copenhagen.

Correspondence to: bso@irct.org
Léonce Byimana ${ }^{1}$, Feride Rushiti ${ }^{2}$, Kolbassia Haoussou ${ }^{3}$ and Vasfije Karsniqi-Goodman ${ }^{4}$ walked us through these questions. The discussion was enhanced with inputs from other IRCT-members.

\section{Why should we engage survivors?}

To understand the relevance of engaging survivors in the global anti-torture work, one could $\mathrm{t}$ reflect on the following question: "Between the person who cooks the cake, and the person who eats the cake - who is the best one to answer the question on 'how does the cake taste??" - Kolbassia Haoussou

This strong-willed question places the survivors as ultimate experts and reflects their relevance in the global work on torture prevention and rehabilitation. Torture survivors are masters of their own experience and deeply understand other survivors' mindsets. Consequently, they are powerful entities for advocating and contributing to the global fight against torture (Byimana, 2021; Haoussou, 2021). 
At a macro-level, survivors' stories can have a massive impact on the social perception and knowledge of torture and policy-making related to the practice of torture and the culture of impunity. By speaking up and telling their stories, survivors can sometimes be more powerful than statistics or research, even with policy-makers, since it brings the human aspect behind the data (Byimana, 2021).

One good example of this is the case of Vasfije Krasniqi-Goodman, who got her case re-opened only after sharing her story publicly. Ever since she became an activist, she has given testimony at the US congress for the Kosovo war crimes done by Serbians and at the UN in New York and Geneva, among other places. This gave survivors some hope that justice could be reached, she claimed (Karsniqi-Goodman, 2021). Her case demonstrates the immense impact of speaking up publicly, while it also reflects the institutional negligence of justice in assessing her case:

\section{"After the war ended, the UN came to Kosovo. I believed so much in their justice and their right-doing that I reported my case to them. Unfortunately, the UN did not do any- thing for my case - I am not sure they looked at it. [...] when my case reached the supreme court in Kosovo, I was denied justice. To me, it felt worse than being tortured because when justice is denied, that is something that hurts you even more after the crime is done."- Vasfije Krasniqi-Goodman}

She now continues to advocate for justice, combating stigma and empowering other survivors. As a current Member of the Kosovan Parliament, she hopes to bring justice to the more than 20.000 survivors of the Kosovan war by holding the perpetrators accountable for their war crimes (Karsniqi-Goodman, 2021).
Another good example is Sister Diana Ortiz, who decided to share her story and founded TASSC to provide a platform for other survivors to speak up (Byimana, 2021).

At a meso-level, survivors can help identify other survivors among their communities and serve as a robust referral mechanism, encouraging reluctant and fearful survivors. They can also form a strong support network at a community level, which guarantees ongoing and long-term support even in the most challenging contexts (Walker, 2021).

Some of the IRCT-member centres already serve as an example of a well-functioning, survivor-led and survivor-implemented organisation. Survivor empowerment is now central to the strategic functioning of Freedom from Torture, $60 \%$ of the Tree for Life team are survivors, and all directors from TASSC and half of its board are survivors. This shows the direct access to and impacts the organisations' decision-making regarding the services provided and advocacy (Byimana, 2021; Haoussou, 2021; Rushiti, 2021; Walker, 2021).

At a micro-level, engaging survivors can have a double-valuable therapeutic effect. Survivors can play a crucial role in helping and supporting other survivors throughout their healing process. Sharing their own traumatic experiences engenders a sense of closeness between them. They also embody the sense of hope that their lives will be rebuilt. Simultaneously, helping others heal is an integral part of the therapeutic process for the survivors who deliver such support. This gives them a sense of agency, self-worth and empowerment (Walker, 2021).

"Working with survivors of torture has helped me to heal from my trauma, and the process has helped to understand that the journey of healing is not a one-day thing, but it is a process" - Tree of Life Field Officer 
They also claim that it has contributed considerably to their resilience, and some have decided to become politically active again, despite the risks (Walker, 2021).

Similarly, being engaged in advocacy positively contributes to their mental health and self-esteem, as their feeling of usefulness in influencing policy-making and social perception of torture increases. $70 \%$ of the torture survivors who access TASSC were previously activists, whistle-blowers, human right defenders and advocates back in their countries and tortured for this reason. After being tortured to be silenced, having the platform to speak up and share their stories is a powerful opportunity for them. Supporting these individuals continue to advocate is only natural for them (Byimana, 2021).

\section{Building the bridge and creating the platform}

In survivor engagement, we must create a platform that will allow survivors to reach and contribute to the anti-torture world, functioning as a bridge to connect them with the broader society and institutions (Byimana, 2021; Haoussou, 2021; Rushiti, 2021).

Following the survivor engagement model, attention is given to integrating a survivor-centric approach in rehabilitation services. It entails adopting an individual approach by looking at the survivor as a unique entity, listening carefully to her or his needs and promote her or his rights in their best interest. In this process, it is of utmost importance to set joint goals with the survivor. Survivors may have different goals (protection, therapy, rehabilitation, justice, etc.), and the service should help them achieve these goals. It is equally important to fully understand these objectives and assess their feasibility against the centre's capacity to provide the necessary means to accomplish them and manage the survivor's expectations. Sometimes the capacity of the centre cannot cover all their requests, and this needs to be clarified (Rushiti, 2021).

This model must be founded on the survivors' willingness to be engaged without pressure on them to do so. Likewise, the purpose for engaging should be well outlined. The objectives can differ from empowering other survivors to seek justice to break myths and stereotypes or be role models for other survivors (Haoussou, 2021; Rushiti, 2021). Most survivors decide to advocate, do it for their communities' safety back home, empower other survivors to do the same, and seek justice (Byimana, 2021).

The presenters also highlighted the importance of creating a safe space for the survivors to engage. Torture survivors, especially those who have suffered from sexual violence, are fragile and sensitive. It is crucial to provide a protected space and ensure confidentiality throughout the process (Haoussou, 2021; Rushiti, 2021). Feride Rushiti shared her organisations' experience supporting Vasfije Karsniqi- Goodman as the first survivor to appear in public and share her story in Kosovo. Aspects such as soft light and direct eye contact with her family and psychologist while testifying in the courtroom were considered to ensure a safe space where she could feel comfortable in telling her story. Moreover, the momentum chosen for the survivor to speak up can also increase and maximise its impact. The exposure of Vasfije's case was a breaking point for Kosovan society and mobilised high institutions (Rushiti, 2021).

Engaging torture survivors also requires re-visiting the question of power (im)balance at an organisational level. As service providers, we hold significant power, influencing how the safe and confident space is shaped. In the process of engaging torture survivors, power needs to be shared with survivors. They are a reliable source of knowledge regarding the 
quality of the services provided, and power imbalance might affect the confidence of survivors to provide trustworthy feedback on the rehabilitation process, fearing they might be denied those services if the feedback is negative. Hence, together with a safe space, cultivating balanced power relationships with survivors will help us build a sense of trust and confidence, bring us closer to their reality and recognise their capacities (Haoussou, 2021).

\begin{abstract}
"You need to understand that you need to share power, create the space for people to engage, and when it comes down to your services, the people that are using your services are the real experts, nobody else." - Kolbassia Houssou
\end{abstract}

\section{Challenges to engaging survivors}

Engaging torture survivors may be challenging for several reasons. On the one hand, telling your story as a survivor is always painful and may bring distressing memories. If revealing their identity may also put their families back home in danger. Moreover, it may jeopardise their legal asylum process if their story is not fully compliant with the one stated on the application (Byimana, 2021). There is also the concern that it may be an obstacle for survivors to digress from the 'survivor identity'. This is why it is relevant to assess the survivor's maturity, resilience, and potential psychosocial consequences (Rushiti, 2021). Likewise, the panellists insist on the voluntary aspect of survivor engagement, ultimately making their own decision to speak up and face these risks (Byimana, 2021; Haoussou, 2021; KarsniqiGoodman, 2021; Rushiti, 2021).

Lynn Walker explains that, given the Zimbabwean context of ongoing use of torture, collective violence and impunity for the perpetrators, survivors in their organisation do not engage in advocacy actions since it would be overly dangerous. Nevertheless, for survivors helping other survivors throughout their healing process, self-care and survivors' well-being are critical. In that sense, care for the caregivers and monitoring the well-being of the survivors must be an integral aspect of our work (Walker, 2021).

On the other hand, engaging survivors also represents a challenge at an organisational level. It involves changes in the organisational structures, internal procedures and decision-making processes, implying power imbalance. Nonetheless, solid leadership and a theory of change that puts survivor engagement at the centre may facilitate this transition. In any case, re-formulating the organisational structure and power balance is paramount to allow survivors to assume leadership (Haoussou, 2021).

\section{Conclusion}

Successful survivor engagement entails identifying challenges at a personal and organisational level and adjusting tactics to respond to the challenges and provide opportunities to overcome them. If managed successfully within an organisation, survivor engagement can contribute positively to the prevention and rehabilitation of torture. When a torture survivor shares her or his story, it can strongly impact advocacy, policy-making, and their rehabilitation journey. When a torture survivor engages in helping other survivors throughout their healing process, it can positively affect both. Given that each survivor's care and wellbeing is of paramount importance, the tactics used will differ in each context. However, the overriding message from the IRCT webinar is that more survivor engagement will improve torture rehabilitation services and, therefore, more member centres should consider this and take action. 


\section{References}

Byimana, L. (2021). Survivor engagement: different approaches for different contexts [Video]. https:// fabo.org/irct/irctmultimedia/resource/25246-30march-survivor-engagement

Haoussou, K. (2021). Survivor engagement: different approaches for different contexts [Video]. https:// fabo.org/irct/irctmultimedia/resource/25246-30march-survivor-engagement

Karsniqi-Goodman, V. (2021). Survivor engagement: different approaches for different contexts [Video]. https://fabo.org/irct/irctmultimedia/ resource/25246-30-march-survivor-engagement Rushiti, F. (2021). Survivor engagement: different approaches for different contexts [Video]. https:// fabo.org/irct/irctmultimedia/resource/25246-30march-survivor-engagement

Walker, L. (2021, April). Personal interview. 